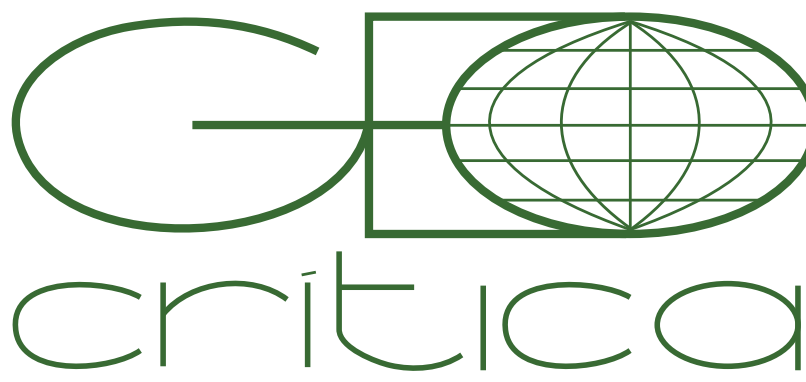

\section{Scripta Nova}

Revista Electrónica de Geografía y Ciencias Sociales Universitat de Barcelona

\title{
RENTA SALARIAL, DESIGUALDAD Y SEGREGACIÓN RESIDENCIAL EN LAS CIUDADES MEDIANAS DE CATALUÑA
}

\author{
Rafa Madariaga \\ rafa.madariaga@uvic.cat \\ Joan Carles Martori \\ martori@uvic.cat \\ Ramon Oller \\ ramon.oller@uvic.cat \\ Universitat de Vic - Universitat Central de Catalunya
}

Recibido: 05 marzo 2019; Devuelto para correciones: 21 marzo 2019; Aceptado: 29 julio 2019

\section{Renta salarial, desigualdad y segregación residencial en las ciudades medianas de Cataluña (Resumen)}

Este trabajo presenta los resultados de un proyecto de investigación sobre las condiciones socioeconómicas en las ciudades medianas de Cataluña. Estas ciudades, que caracterizan el sistema policéntrico catalán y también el europeo, han recibido menos atención que las ciudades grandes y globales. A partir de una estimación de la renta salarial media para cada una de las 41 ciudades seleccionadas, se analiza la relación con la desigualdad y la segregación residencial por ingresos y de la población inmigrante. Durante el periodo analizado (2001-2011), se observa una reducción de la renta salarial y de un aumento de la segregación de las rentas bajas y de la población inmigrante. Esta tendencia general presenta variaciones importantes entre las nueve ciudades más grandes, capitales provinciales y capitales comarcales localizadas en la Región Metropolitana de Barcelona y las que no son capitales comarcales, algunas localizadas en la RMB y otras fuera de ese ámbito.

Palabras clave: Desigualdad, segregación residencial, Renta salarial, ciudades medianas

\section{Wage Income, inequality and residential segregation in median Catalo- nian cities (Abstract)}

This article presents the results of a research project focused on median Catalonian cities. This kind of cities, which characterize Catalonian polycentric urban system and European urban system, have received less attention than large global cities. An estimation of the wage income for 41 cities allows analysing the relationship with income inequality and income and immigrant population residential segregation. Along the period (2001-2011), a reduction in wage income, decreasing inequality and high-income segregation and increasing low-income and immigrant population segregation is observed. This general pattern presents variability between the nine largest cities, provincial capitals and county capitals located in the Barcelona Metropolitan Region and the 22 cities that are not county capitals, some in the BMR and others outside this grouping.

Keywords: Inequality, residential segregation, wage income, median cities 
El análisis del papel de las ciudades en el crecimiento económico ha estado en el centro del desarrollo de la geografía económica, la economía urbana y la ciencia regional. En la década de los años 90 del siglo pasado, gracias a algunas obras seminales $^{1}$, hubo un redescubrimiento de la importancia del vínculo entre el crecimiento económico y el papel de las ciudades que dio lugar a importantes aportaciones. En los orígenes de ese impulso hay que situar, por un lado, los desarrollos teóricos y empíricos para el estudio de las Economías de Aglomeración y por otro, la creación y expansión de las tecnologías de la información y la comunicación (TIC) y el papel preponderante de la globalización. En el caso europeo, también hay que destacar la creación del mercado único europeo, que supuso un aumento significativo de la inversión extranjera directa (FDI), localizado principalmente en las grandes ciudades². La expansión de las TIC y la globalización ha dado lugar a una segunda línea de literatura que enfatiza la importancia de las redes de innovación y conocimiento. El grueso de la investigación se ha dedicado al análisis de las grandes ciudades por considerarlas el lugar donde se producen las economías de aglomeración y los nodos de conexión entre los flujos de ideas y conocimientos que juegan un papel clave en la economía globalizada. En palabras de David y sus coautores ${ }^{3}$, tanto el paradigma de las economías de aglomeración como el de las redes globales implican que "más grande es mejor". Menos atención se ha dedicado a la investigación de las condiciones económicas en las ciudades medianas o ciudades de segundo orden 4 . Diversas aportaciones recientes ${ }^{5}$ han discutido en términos teóricos y empíricos el predominio de las grandes ciudades en el estudio del crecimiento económico. Este estudio contribuye al debate presentando los resultados de una estimación de la renta salarial para 41 ciudades medianas de Cataluña. La renta salarial es el conjunto de salarios recibidos por los ocupados y constituye la mayor parte de la renta total 6 , en la que también deben tenerse en cuenta los ingresos derivados de la propiedad del capital (acciones, otros activos financieros y propiedades) y las transferencias públicas, básicamente las pensiones y otros tipos de subsidios y ayudas públicas.

El aumento de la desigualdad en las sociedades avanzadas es una de las cuestiones más acuciantes del siglo XXI. El análisis de sus causas y de las adversas consecuencias sociales, económicas y políticas que implica ocupa buena parte de la investigación en las ciencias sociales. Incluso organismos internacionales como el Banco Mundial, el FMI o la OCDE, tradicionalmente poco preocupados por asuntos

1 Glaeser et al. 1992, Krugman, 1991a

2 Camagni et al. 2015

3 "Bigger is better". David et al. 2013

4 Más adelante explicamos con detalle la tipología de ciudad a la que nos referimos. Sobre los problemas para la definición de ciudades medianas, Andrés 2008. Sobre la evolución en la definición de tipologías de sistemas urbanos, Roca et al. 2012. Para una perspectiva europea, Dijkstra y Poelman, 2014

5 Dijkstra et al. 2013, David et al. 2013, Camagni et al. 2015 y Parkinson et al. 2015

6 En 2015, el 61,4\% de la Renta Familiar Bruta disponible en Cataluña corresponde a la Remuneración de Asalariados. (https://www.idescat.cat/pub/?id=rfdbc\&n=8226 Consulta: Enero 2019). Brindusa et al. 2018, p. 17. 
distributivos, han aumentado recientemente su atención sobre el tema ${ }^{7}$. Dado que el $54 \%$ de la población mundial vive en las ciudades ${ }^{8}$, estas son el principal escenario donde la desigualdad se muestra en forma de graves diferencias en las condiciones de vida, en el acceso a la educación, la salud y otros servicios públicos y en conflictos sociales. Hay que tener en cuenta también que el análisis de la desigualdad requiere definir con precisión a qué tipo de variable se refiere: la riqueza, la renta, los ingresos salariales u otras dimensiones. Este trabajo, por razones de disponibilidad de información se basa en una estimación de la renta salarial. Aunque se han estudiado diferentes escalas geográficas de la desigualdad (grandes zonas, países, regiones, ciudades) es en las ciudades donde el fenómeno se manifiesta en toda su extensión, ya que constituyen un espacio compartido y común para la vida social. Además, las intervenciones políticas que pretenden combatir la desigualdad tienen efectos diferentes en el ámbito urbano dada la intensa movilidad que lo caracteriza. La gran mayoría de la investigación de la desigualdad urbana se ha centrado en grandes metrópolis, ciudades globales y conectadas que concentran la mayoría de la población.

Estudios recientes, como el de Florida ${ }^{9}$, aportan una perspectiva poco halagüeña sobre el futuro de esas grandes ciudades donde la creciente desigualdad va acompañada de una intensa segregación residencial y de una polarización creciente de las sociedades. Uno de los objetivos de esta línea de investigación es analizar si esos resultados son extrapolables a las ciudades medianas o si, por el contrario, estas presentan dinámicas sociales y económicas diferentes. Existe una amplia bibliografía centrada en el estudio de la relación entre desigualdad y diferentes aspectos de la segregación residencial (ingresos, niveles educativos, ocupaciones, nacionalidades) ${ }^{10}$. Por ejemplo, Reardon y Bischoff constatan, analizando las cien áreas metropolitanas más pobladas de EE. UU., una relación fuerte y robusta entre la desigualdad de ingresos y la segregación por ingresos. Según sus resultados, el aumento de la desigualdad de ingresos causa entre un 40 y un $80 \%$ de la segregación por ingresos entre 1970 y 2000, una época en la que la desigualdad de ingresos aumentó de manera significativa. Sus resultados indican que la relación es más débil en las áreas metropolitanas más pequeñas. La desigualdad de ingresos afecta a la segregación mediante la separación de los más ricos en mucha mayor medida que la de los más pobres. En su opinión, son las familias con mayores niveles de ingresos las que disponen de mayores posibilidades para decidir la localización ${ }^{11}$. En cambio, la segregación de las familias menos favorecidas tiene más relación con las políticas públicas de vivienda. Musterd y sus coautores analizan la segregación socioeconómica en doce grandes capitales europeas. Sus resultados muestran que el aumento progresivo de la segregación va en paralelo al aumento de la desigualdad en un proceso que está

7 OECD, 2011, 2015, Dabla-Norris et al. 2015; World Bank 2016

8 World Bank. World Development Indicators, 2016 https://datacatalog.worldbank.org/dataset/ world-development-indicators [Consulta: Febrero 2019]

9 Florida, 2017

10 Reardon y Bischoff 2011, Van Ham et al. 2015, Musterd et al. 2017, Quillian y Lagrange 2016.

11 En el mismo sentido, Tammaru et al. 2019 
presente en todas las ciudades analizadas. A pesar del aumento general de la segregación en la década que analizan (2001-2011), constatan que la diferencia con los niveles de USA aún es importante. Analizan también el papel que juegan cuatro variables estructurales: el aumento de la desigualdad socioeconómica, la limitación de las políticas propias del estado del bienestar, la reestructuración económica que acompaña al desarrollo de la globalización, la creciente liberalización del mercado de la vivienda y la consecuente reducción del protagonismo de la política de vivienda pública. Todos estos factores, y especialmente el primero, contribuyen de manera significativa al aumento de la segregación socioeconómica.

Cataluña se caracteriza por un sistema urbano policéntrico, dominado por la existencia de una gran metrópolis global; Barcelona y su área metropolitana. La distribución de la población (datos del Censo 2011) indica que un $40 \%$ de la población de Cataluña reside en los 36 municipios que conforman el AMB, un 30\% en 41 ciudades de más de 20.000 habitantes $^{12}$ y otro $30 \%$ en los más de 800 municipios restantes. Este trabajo presenta algunos de los resultados de un proyecto de investigación sobre las condiciones socioeconómicas de las ciudades medianas. Concretamente, se presentan resultados sobre el nivel de renta salarial, de desigualdad y de segregación residencial en esas 41 ciudades medianas de Cataluña. La preeminencia del AMB, su peso poblacional y su consideración de ciudad global ha limitado la atención prestada al análisis de otras realidades urbanas que también forman parte importante de la geografía de Cataluña. El objetivo de la investigación es aportar evidencia empírica sobre las condiciones socioeconómicas en ese tipo de ciudades. Además, este sistema urbano policéntrico, menos concentrado en grandes ciudades es representativo del sistema urbano europeo. Según la Comisión Europea ${ }^{13}$, el 38\% de la población europea reside en ciudades pequeñas y medianas, lo que representa el $56 \%$ de la población urbana. El análisis de las condiciones económicas y sociales en estas ciudades medianas de Cataluña contribuye a ampliar la perspectiva sobre las dinámicas urbanas y aporta evidencia indirecta sobre el sistema urbano europeo. Con ese objetivo, se ha desarrollado y aplicado un método estadístico para estimar la renta salarial por sección censal para las 41 ciudades medianas de Cataluña en 2001 y 2011 y se han calculado índices de desigualdad y de segregación residencial de la población con menores y mayores ingresos salariales y de la población inmigrante. Posteriormente, se ha aplicado un análisis cluster para obtener una tipología de ciudades en función de sus características socio-demográficas. Los resultados de esta línea de investigación y de este trabajo en particular aportan evidencia empírica sobre una realidad socio-económica escasamente analizada de manera sistemática y sirven para desarrollar políticas públicas que potencien un desarrollo más equilibrado entre el AMB y el sistema urbano policéntrico catalán.

12 El límite de 20.000 habitantes es el que utiliza el Ministerio de fomento en su metodología para la delimitación del primer subsestrato de las pequeñas áreas urbanas. https://www.fomento. gob.es/portal-del-suelo-y-politicas-urbanas/atlas-estadistico-de-las-areas-urbanas [Consulta: Febrero 2019]

13 European Commission, 2011 
El artículo se estructura de la siguiente manera: en la segunda sección se presentan brevemente el conjunto de ciudades analizado, el método para la estimación de la renta salarial y los métodos para el cálculo de los índices de desigualdad y de segregación. La tercera sección presenta los resultados obtenidos. En la cuarta, se expone la aplicación y las variables utilizadas para el análisis cluster y se presentan los resultados y en la quinta se sintetizan un conjunto de conclusiones y se proponen algunas líneas para futuras investigaciones.

\section{Datos y métodos}

La figura 1 presenta el mapa de las ciudades analizadas y en la tabla 2 aparecen ordenadas por la población de 2011 . Como puede apreciarse, el conjunto de ciudades medianas contiene las capitales de provincia excepto Barcelona, municipios situados en la periferia del AMB que pertenecen a la Región Metropolitana de Barcelona (RMB), un buen número de capitales de comarca y algunas ciudades que no son capitales de comarca.

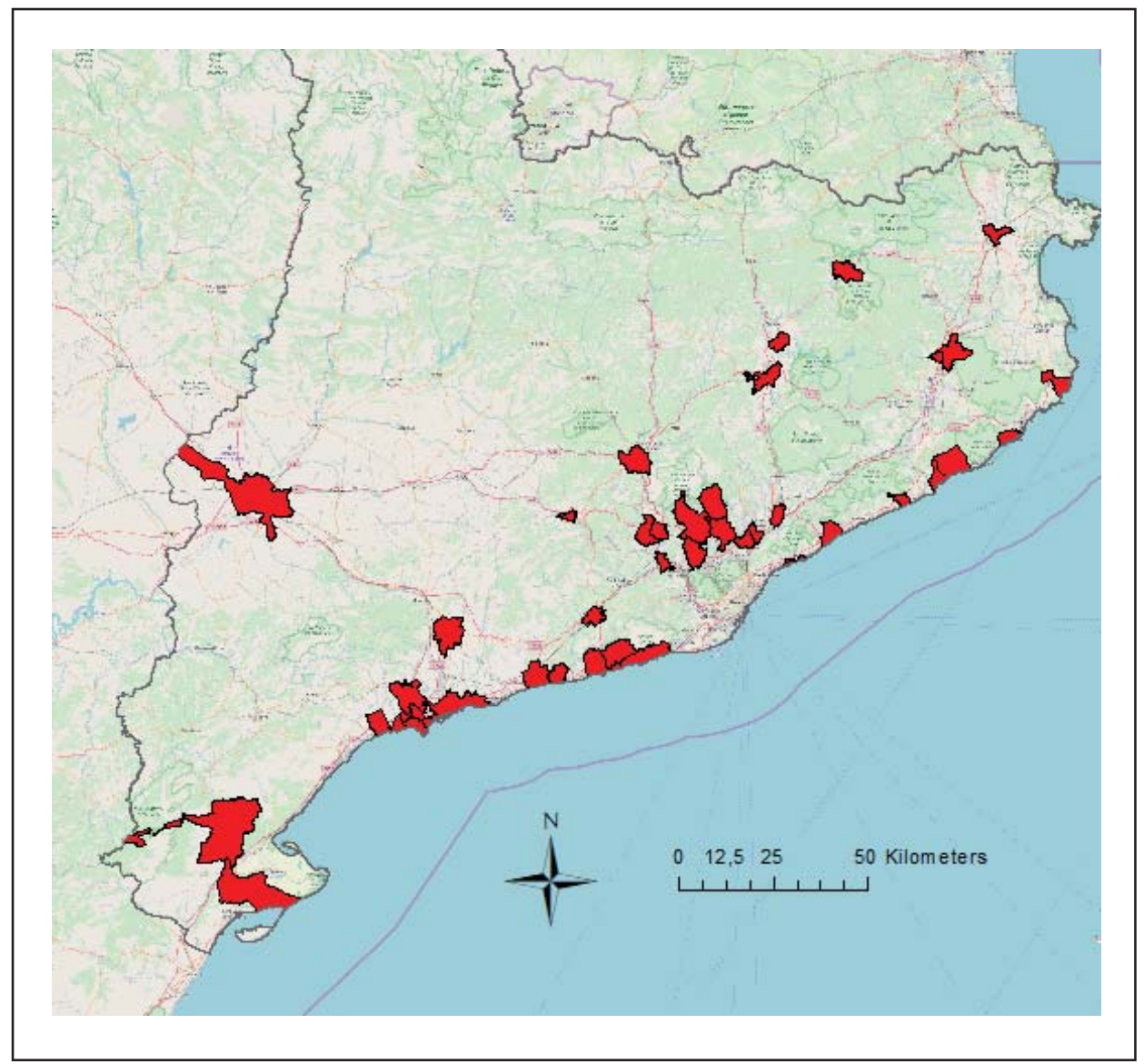

Figura 1. Mapa de las 41 ciudades medianas de Cataluña

El conocimiento y la disponibilidad de información sobre macromagnitudes económicas para áreas urbanas presenta algunas dificultades en España, a pesar de las recientes aportaciones realizadas por diversos organismos ${ }^{14}$. En otra publicación

14 Desde 2016. la agencia tributaria publica datos sobre las declaraciones del IRPF por 
hemos realizado un análisis más completo de las fuentes disponibles en Cataluña que proporcionan estimaciones del nivel de renta ${ }^{15}$. También presenta una explicación más detallada y formal del método de estimación de la renta salarial que hemos utilizado.

La estimación de la renta salarial se ha realizado enlazando información de los censos de 2001 y 2011 con información de salarios obtenida de las Encuestas de Estructura Salarial de 2002 y 2010. Los salarios de 2002 se han actualizado utilizando el índice de precios al consumo. Los censos proporcionan, para cada sección censal, el número de ocupados por ocupación y sector de actividad. Las Encuestas de Estructura Salarial proporcionan una distribución de salarios brutos anuales correspondientes a las mismas categorías de ocupación y sector económico. Para enlazar las categorías de ocupación y sector económico de ambas fuentes, hemos utilizado una tabla de doble entrada con 8 ocupaciones y 11 sectores económicos. Es decir, hemos considerado un total de 88 celdas. Dado el recuento de cada una de las secciones censales, hemos llevado a cabo una selección aleatoria de salarios con reposición de la correspondiente celda. El método genera una distribución de salarios para cada sección censal, que es la base del cálculo de la renta salarial, la desigualdad y los índices de segregación por nivel de ingresos. La renta salarial estimada se obtiene sumando el total de salarios imputados y dividiendo por el número de ocupados que se han tenido en cuenta en cada sección censal. La variable estimada es la renta salarial media por ocupado y por sección censal.

El método tiene algunas implicaciones que deben considerarse para interpretar los resultados. En primer lugar, hemos utilizado salarios brutos anuales, dado que no podemos saber el salario neto que depende de características específicas de cada ocupado sobre las que no tenemos información. En segundo lugar, para obtener la distribución de salarios en cada celda hemos seleccionado solamente trabajadores con contratos indefinidos a tiempo completo. Ambos factores tienden a sobrestimar la renta salarial. Por otro lado, debe tenerse en cuenta que la renta salarial es una parte de la renta familiar disponible. No disponemos de información sobre rentas del capital y de la propiedad ni de ingresos obtenidos por subsidios, pensiones $\mathrm{u}$ otras ayudas. Por último, debe ponderarse el hecho de que utilizar la sección censal permite tener un detalle espacial superior al de todas las fuentes disponibles y que permite obtener indicadores para cada ciudad teniendo en cuenta su estructura interna: la renta salarial de cada municipio tiene en cuenta la renta media de todas las secciones censales que la constituyen.

A partir de las distribuciones de salarios por sección censal hemos calculado la desigualdad utilizando el índice de Gini. Esta medida presenta algunas ventajas. Como es bien sabido, varía entre 0 (perfecta igualdad) y 1 (perfecta desigualdad) y tiene una interpretación sencilla relacionada con la curva de Lorenz y un uso ge-

municipios: https://www.agenciatributaria.es/AEAT.internet/datosabiertos/catalogo/hacienda/ Estadistica del IRPF por codigo postal.shtml [Consulta: Febrero 2019]

15 Madariaga et al. 2012 
neralizado que permite comparar los resultados con otros disponibles a nivel de ciudades, áreas metropolitanas y países. También obtenemos otras medidas descriptivas de la distribución que permiten medir la desigualdad: las ratios que miden la distancia entre el percentil 90 y el 50 (P90/P50) para analizar la mitad superior de la distribución y entre el percentil 50 y el 10 (P50/P10) para analizar la mitad inferior.

Los índices de segregación residencial se pueden agrupar en cinco dimensiones ${ }^{16}$ : igualdad, exposición, concentración, agregación o agrupamiento espacial y centralización. Los primeros hacen referencia a la igualdad en la distribución de uno o más grupos en las unidades espaciales en que podemos dividir un espacio urbano. Así, la segregación es un reparto desigual entre las unidades espaciales de la ciudad. Los índices de exposición se relacionan con el grado de contacto potencial, o bien, con la posibilidad de interacción entre los miembros de un mismo grupo, o entre miembros de dos grupos diferentes. Los de concentración hacen referencia a la ocupación por parte de un grupo de un espacio particular en términos de superficie. Según esta dimensión, cuanto más pequeña sea la parte del espacio urbano que ocupa un grupo, más concentrado, y por lo tanto más segregado estará el colectivo. Los índices de agregación espacial analizan la posible ocupación de zonas contiguas por un grupo de población, de modo que puede constituirse en un enclave dentro de la ciudad (un ghetto o un enclave étnico); en este sentido, cuanto más agrupado se encuentra el grupo más alta es su segregación. Por último, los índices de centralización miden la proximidad de un grupo de población al centro urbano. Según estos índices, cuanto mayor sea la presencia de un grupo en el centro de la ciudad, más segregado estará. El origen de este último tipo de índices es la situación de las ciudades norteamericanas, donde las minorías afro americanas se asentaban en las zonas céntricas deterioradas, poco atractivas para la mayoría de población blanca. Dado que dependen de una etapa histórica concreta de las dinámicas urbanas y dadas las dimensiones y la superficie de las ciudades analizadas no hemos calculado ni utilizado este tipo de índices.

Hemos calculado todos los índices correspondientes a las cuatro dimensiones seleccionadas pero solo presentamos los resultados del índice de aislamiento con distancia decreciente ${ }^{17}$ (DPXx) correspondiente a la dimensión de agregación espacial porque es el único que presenta coeficientes de correlación significativos con el índice de Gini. Varía entre 0 (mínima segregación) y l (máxima segregación). Los cálculos se han realizado con Geosegregation Analyzer ${ }^{18}$.

\section{Resultados}

La primera cuestión sobre la que centramos nuestra atención es la distribución de los salarios en el conjunto de las 41 ciudades analizadas. La tabla 1 presenta algunos datos descriptivos de todos los salarios considerados.

16 Massey y Denton, 1988

17 Morgan, 1983

18 Apparicio et al. 2014 
Tabla 1. Renta Salarial ciudades medianas. Descriptivos.

\begin{tabular}{cccccccc}
\hline \multicolumn{10}{c}{001} \\
$\mathbf{N}$ & $\mathbf{P 1 0}$ & $\mathbf{P 2 5}$ & Media & Mediana & P75 & P90 & Gini \\
\hline 729.534 & 13.233 & 15.950 & 28.130 & 21.870 & 32.110 & 48.254 & 0,3248 \\
& & \multicolumn{7}{c}{2011} & & & \\
\hline 1.037 .280 & 12.974 & 16.160 & 26.610 & 21.560 & 30.810 & 43.917 & 0,3037 \\
\hline
\end{tabular}

Fuente: Elaboración propia con datos del censo, INE e Idescat.

Se muestra el número de individuos que se han utilizado para la estimación, la Renta Salarial media, la mediana, los valores límite correspondientes a diferentes percentiles y el índice de Gini. A lo largo del periodo se ha producido una reducción general de los salarios en las ciudades medianas. La media se ha reducido un 5,4\% y la mediana, un 0,14\%. Esta reducción de los salarios es el resultado, por un lado, de la "deflación salarial" que tuvo lugar después de la crisis financiera (2008) y cuyos resultados se han documentado en diversos trabajos ${ }^{19}$, y de la destrucción de empleo. En segundo lugar, se aprecia que todos los límites de los percentiles se reducen, excepto el límite del percentil 25 (P25), que aumenta. En tercer lugar, el límite del percentil 90 (P90) es el que ha experimentado la mayor reducción (8,98\%). Por último, se aprecia que la reducción de los salarios ha implicado una reducción del índice de Gini.

La tabla 2 presenta, ordenados de mayor a menor según la población de 2011 , los municipios analizados, los valores de la renta salarial y del índice de Gini y su ordenación de mayor a menor. Puede apreciarse que los cinco municipios con mayor renta salarial en 2011 son Sitges, El Masnou, Castellar del Vallés, Igualada y Cambrils. Los cinco municipios con menor renta salarial son Palafrugell, Lloret, Salt, Sant Feliu de Guíxols y Blanes. En cuanto a la desigualdad, los municipios donde el índice de Gini es más elevado son Sitges, El Masnou, Castellar del Vallés, Igualada y Premià de Mar. En el otro extremo y por orden aparecen Salt, Palafrugell, Amposta, Blanes y Sant Feliu de Guíxols. El coeficiente de correlación entre la renta salarial y la desigualdad es 0,932 en 2011 , positivo y significativo (ver tabla 4). Además, esta correlación positiva ha aumentado respecto a 2001, cuando el coeficiente de correlación era de 0,858. Es decir, los municipios con mayor renta salarial son también los que presentan mayor desigualdad y esta asociación positiva se ha reforzado a lo largo del periodo. Este resultado coincide con los obtenidos en la literatura empírica que analiza la desigualdad urbana ${ }^{20}$. El principal determinante de la desigualdad urbana es la renta: cuanto mayor es el nivel de renta, mayor es el nivel de desigualdad. Además, esta relación directa se ha mantenido también en un periodo en el que se ha reducido la renta.

19 Por ejemplo, Tilford 2015, Uxó et al. 2016 y Brindusa et al. 2018.

20 Glaesser et al. 2009, Lee et al. 2016, Bolton y Breau 2012, Madariaga et al. 2019. 


\begin{tabular}{|c|c|c|c|c|c|}
\hline Municipio & Población & Renta Salarial & Orden & Î́ndice Gini & Orden \\
\hline Terrassa & 213.697 & $26.901,02$ & 16 & 0,3037 & 16 \\
\hline Sabadell & 207.721 & $27.412,55$ & 9 & 0,3094 & 9 \\
\hline Lleida & 138.416 & $26.726,79$ & 18 & 0,3048 & 12 \\
\hline Tarragona & 134.085 & $27.490,94$ & 8 & 0,3075 & 11 \\
\hline Mataró & 123.868 & $26.331,05$ & 23 & 0,3006 & 22 \\
\hline Reus & 106.709 & $25.837,55$ & 27 & 0,2952 & 26 \\
\hline Girona & 96.722 & $27.740,94$ & 6 & 0,3146 & 7 \\
\hline Manresa & 76.589 & $27.108,48$ & 12 & 0,3042 & 14 \\
\hline Rubí & 73.979 & $25.590,72$ & 30 & 0,2844 & 36 \\
\hline Vilanova i la Geltrú & 66.905 & $26.975,99$ & 14 & 0,3028 & 19 \\
\hline Granollers & 60.000 & $27.183,74$ & 10 & 0,3087 & 10 \\
\hline Mollet del Vallès & 52.409 & $25.663,50$ & 29 & 0,2899 & 33 \\
\hline Figueres & 44.765 & $24.677,83$ & 35 & 0,2888 & 34 \\
\hline Vic & 40.900 & $27.161,30$ & 11 & 0,3024 & 20 \\
\hline Lloret de Mar & 40.282 & $23.673,35$ & 40 & 0,2922 & 28 \\
\hline Blanes & 39.834 & $24.445,36$ & 37 & 0,2806 & 38 \\
\hline Igualada & 39.191 & $28.022,23$ & 4 & 0,3154 & 6 \\
\hline Vilafranca del Penedès & 38.785 & $27.045,44$ & 13 & 0,3043 & 13 \\
\hline El Vendrell & 36.453 & $25.514,49$ & 31 & 0,2970 & 24 \\
\hline Tortosa & 34.432 & $26.379,74$ & 22 & 0,3020 & 21 \\
\hline Olot & 33.725 & $26.851,07$ & 17 & 0,3039 & 15 \\
\hline Cambrils & 33.008 & $27.966,31$ & 5 & 0,3265 & 3 \\
\hline Salt & 30.389 & $23.694,02$ & 39 & 0,2624 & 41 \\
\hline Sant Pere de Ribes & 28.783 & $26.936,96$ & 15 & 0,3127 & 8 \\
\hline Sitges & 28.617 & $31.636,93$ & 1 & 0,3466 & 1 \\
\hline Premia de Mar & 28.310 & $27.661,93$ & 7 & 0,3157 & 5 \\
\hline Martorell & 27.457 & $26.259,19$ & 24 & 0,2965 & 25 \\
\hline
\end{tabular}




\begin{tabular}{lccccc} 
Salou & 26.193 & $24.758,59$ & 34 & 0,2978 & 23 \\
Pineda de Mar & 26.040 & $24.976,63$ & 33 & 0,2880 & 35 \\
Santa Perpètua de M. & 25.331 & $26.631,11$ & 19 & 0,2948 & 27 \\
Valls & 25.016 & $26.470,71$ & 21 & 0,3030 & 18 \\
Calafell & 24.984 & $26.185,66$ & 25 & 0,3033 & 17 \\
Olesa de Montserrat & 23.924 & $26.598,37$ & 20 & 0,2911 & 31 \\
Castellar del Vallès & 23.238 & $28.559,92$ & 3 & 0,3217 & 4 \\
Palafrugell & 22.816 & $23.509,55$ & 41 & 0,2693 & 40 \\
El Masnou & 22.523 & $30.148,88$ & 2 & 0,3373 & 2 \\
Esparreguera & 21.986 & $25.820,70$ & 28 & 0,2908 & 32 \\
Vila-seca & 21.839 & $25.358,20$ & 32 & 0,2920 & 29 \\
Sant Feliu de Guíxols & 21.814 & $24.021,06$ & 38 & 0,2837 & 37 \\
Amposta & 21.445 & $24.584,91$ & 36 & 0,2754 & 39 \\
Manlleu & 20.445 & $25.885,24$ & 26 & 0,2919 & 30 \\
\hline
\end{tabular}

Fuente: Elaboración propia con datos del censo, INE e Idescat.

Tabla 3: Índices de segregación por municipios y posición en el orden.

\begin{tabular}{|c|c|c|c|c|c|c|}
\hline Municipio & DPxx10 & Orden & Dpxx90 & Orden & DPxx & Orden \\
\hline Terrassa & 0,1231 & 23 & 0,0696 & 14 & 0,1429 & 26 \\
\hline Sabadell & 0,1223 & 27 & 0,0769 & 7 & 0,1155 & 30 \\
\hline Lleida & 0,1174 & 32 & 0,0657 & 19 & 0,1700 & 11 \\
\hline Tarragona & 0,1197 & 29 & 0,0709 & 13 & 0,1485 & 21 \\
\hline Mataró & 0,1239 & 22 & 0,0633 & 21 & 0,1473 & 23 \\
\hline Reus & 0,1291 & 14 & 0,0581 & 26 & 0,1634 & 16 \\
\hline Girona & 0,1299 & 13 & 0,0847 & 4 & 0,1688 & 13 \\
\hline Manresa & 0,1303 & 12 & 0,0724 & 10 & 0,1685 & 14 \\
\hline Rubí & 0,1183 & 31 & 0,0435 & 36 & 0,1413 & 27 \\
\hline Vilanova i la Geltrú & 0,1224 & 26 & 0,0667 & 18 & 0,1063 & 33 \\
\hline Granollers & 0,1185 & 30 & 0,0752 & 8 & 0,1562 & 18 \\
\hline Mollet del Vallès & 0,1253 & 20 & 0,0560 & 27 & 0,1117 & 31 \\
\hline Figueres & 0,1357 & 8 & 0,0533 & 30 & 0,2856 & 3 \\
\hline
\end{tabular}




\begin{tabular}{|c|c|c|c|c|c|c|}
\hline Vic & 0,1110 & 38 & 0,0675 & 17 & 0,2280 & 5 \\
\hline Lloret de Mar & 0,1562 & 1 & 0,0385 & 39 & 0,2893 & 2 \\
\hline Blanes & 0,1446 & 4 & 0,0484 & 34 & 0,1492 & 20 \\
\hline Igualada & 0,1230 & 24 & 0,0802 & 6 & 0,1099 & 32 \\
\hline Vilafranca del Penedès & 0,1145 & 37 & 0,0696 & 15 & 0,1596 & 17 \\
\hline El Vendrell & 0,1366 & 7 & 0,0553 & 29 & 0,1382 & 28 \\
\hline Tortosa & 0,1310 & 10 & 0,0709 & 12 & 0,2487 & 4 \\
\hline Olot & 0,1219 & 28 & 0,0688 & 16 & 0,1719 & 10 \\
\hline Cambrils & 0,1257 & 18 & 0,0912 & 3 & 0,1982 & 9 \\
\hline Salt & 0,1495 & 3 & 0,0363 & 41 & 0,3624 & 1 \\
\hline Sant Pere de Ribes & 0,1253 & 19 & 0,0717 & 11 & 0,0979 & 35 \\
\hline Sitges & 0,1074 & 41 & 0,1024 & 1 & 0,1690 & 12 \\
\hline Premià de Mar & 0,1224 & 25 & 0,0738 & 9 & 0,1375 & 29 \\
\hline Martorell & 0,1251 & 21 & 0,0624 & 22 & 0,1526 & 19 \\
\hline Salou & 0,1264 & 16 & 0,0459 & 35 & 0,1998 & 8 \\
\hline Pineda de Mar & 0,1309 & 11 & 0,0512 & 31 & 0,1482 & 22 \\
\hline Santa Perpètua de M. & 0,1172 & 34 & 0,0637 & 20 & 0,1012 & 34 \\
\hline Valls & 0,1366 & 6 & 0,0553 & 28 & 0,1657 & 15 \\
\hline Calafell & 0,1334 & 9 & 0,0623 & 23 & 0,1450 & 25 \\
\hline Olesa de Montserrat & 0,1101 & 39 & 0,0623 & 24 & 0,0909 & 37 \\
\hline Castellar del Vallès & 0,1262 & 17 & 0,0831 & 5 & 0,0494 & 41 \\
\hline Palafrugell & 0,1441 & 5 & 0,0371 & 40 & 0,2107 & 6 \\
\hline El Masnou & 0,1161 & 36 & 0,0976 & 2 & 0,0714 & 40 \\
\hline Esparreguera & 0,1274 & 15 & 0,0588 & 25 & 0,0779 & 39 \\
\hline Vila-seca & 0,1098 & 40 & 0,0430 & 37 & 0,0943 & 36 \\
\hline Sant Feliu de Guíxols & 0,1517 & 2 & 0,0510 & 32 & 0,1454 & 24 \\
\hline Amposta & 0,1173 & 33 & 0,0416 & 38 & 0,0864 & 38 \\
\hline Manlleu & 0,1162 & 35 & 0,0508 & 33 & 0,2091 & 7 \\
\hline Media & 0,1262 & & 0,0633 & & 0,1569 & \\
\hline
\end{tabular}

Fuente: Elaboración propia con datos del censo, INE e Idescat.

Nota: DPxx10: segregación del decil inferior. DPxx90: segregación del decil superior. DPxx: segregación de inmigrantes, 2011. 
La tabla 3 presenta los municipios analizados con el mismo orden que la tabla 2, los índices de aislamiento con distancia decreciente para el decil inferior de ingresos (DPxx10), el decil superior (DPxx90) y los inmigrantes no pertenecientes a la UE (DPXx) y el orden de cada ciudad para cada índice ordenados de mayor a menor. Se puede apreciar que, considerando los valores medios, la segregación de la población inmigrante es la mayor, seguida de la segregación de la población con menores ingresos y de la población con mayores ingresos. Destaca también que la segregación de los inmigrantes se ha triplicado entre 2001 y 2011.

Atendiendo a la segregación residencial de la población inmigrante, los cinco municipios con mayores valores son Salt, Lloret, Figueres, Tortosa y Vic. En el otro extremo, aparecen Castellar del Vallès, El Masnou, Esparraguera, Amposta y Olesa de Montserrat.

Respecto a la segregación residencial de la población con mayores ingresos, destacan con valores elevados, Sitges, El Masnou, Cambrils, Girona y Castellar del Vallès. En el otro extremo, la segregación es menor en Salt, Palafrugell, Lloret, Amposta y Vilaseca. En relación a la segregación residencial de la población con menores ingresos los valores mayores se presentan en Lloret, Sant Feliu de Guíxols, Salt, Blanes y Palafrugell y los menores valores son los de Sitges, Vila-seca, Olesa de Montserrat, Vic y Vilafranca del Penedès.

Para analizar la relación entre la renta salarial y la segregación, hemos calculado los índices de correlación. La tabla 4 y la figura 2 presentan los resultados.

Tabla 4. Coeficientes de correlación. 2011

\begin{tabular}{|c|c|c|c|c|}
\hline & DPxx10 & Dpxx90 & DPxx & Media \\
\hline GINI &,$- 470^{* *}$ &, $930^{* *}$ &,$- 320^{*}$ &, $932^{* *}$ \\
\hline DPxx10 & &,$- 473^{* *}$ &, $485^{* *}$ &,$- 635^{* *}$ \\
\hline Dpxx90 & & &,$- 329^{*}$ &, $945^{* *}$ \\
\hline DPxx & & & &,$- 395^{\circ}$ \\
\hline
\end{tabular}

Nota: ** La correlación es significativa al nivel 0,01. * La correlación es significativa al nivel 0,05 

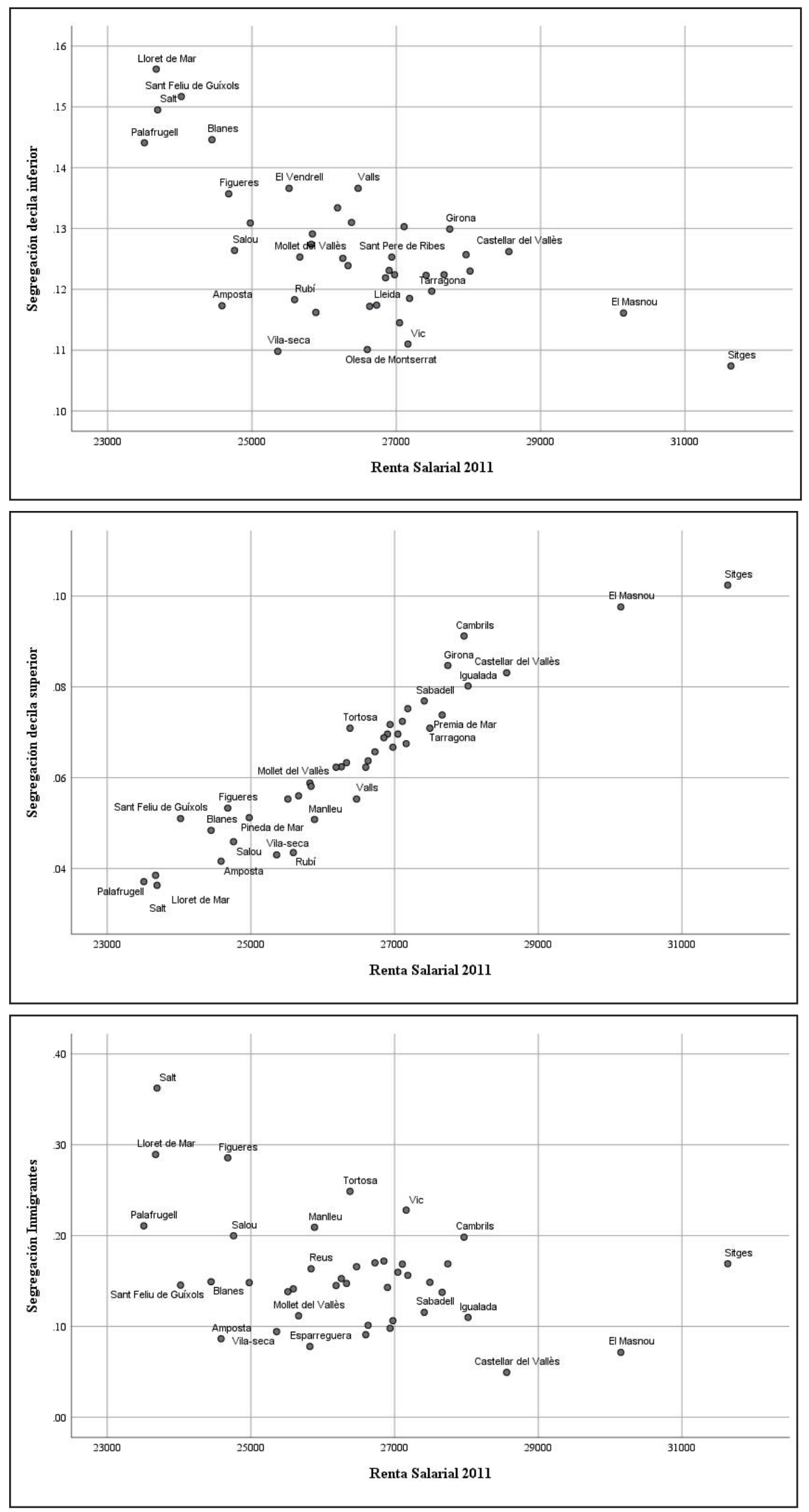

Figura 2. Renta Salarial y segregación: a) segregación del decil inferior. b) segregación del decil superior. c) segregación de inmigrantes. 
En la primera sección de la figura 3 puede apreciarse una clara correlación negativa entre la segregación del decil inferior y la renta salarial. Es decir, aquellos municipios donde los perceptores de rentas salariales bajas están más segregados, la renta salarial es menor. Y también, los municipios con mayores rentas salariales muestran una menor segregación de las rentas bajas. El resultado en la tabla 4 muestra un coeficiente de correlación negativo y significativo. La segunda sección de la figura 3 muestra la relación entre el índice de segregación de los perceptores de rentas salariales elevadas y la renta salarial del municipio. Puede apreciarse claramente una relación positiva. El resultado de la tabla 4 muestra un coeficiente positivo muy elevado y significativo. La segregación de las rentas altas está asociado a mayores valores de la renta salarial. La tercera sección de la figura 3 muestra la relación entre la segregación de la población inmigrantes y la renta salarial. Se observa una mayor dispersión de los valores. El coeficiente de correlación correspondiente en la tabla 4 muestra un valor reducido, negativo y menos significativo que los anteriores. La relación entre la segregación de la población inmigrante y el nivel de renta salarial del municipio es más débil que las que hemos comentado previamente. Por último, hemos analizado la relación entre la segregación y la desigualdad. La figura 3 y la tabla 4 presentan los resultados.

La primera sección de la figura 4 muestra una asociación negativa entre la segregación de los perceptores de rentas bajas y la desigualdad. Se aprecia una relación negativa pero una elevada dispersión. El resultado de la tabla 4 confirma la idea. El coeficiente de correlación es negativo y menor que 0,5, aunque significativo. Existe una relación inversa entre la segregación de las rentas inferiores y la desigualdad. La segunda sección muestra la relación lineal entre la segregación de los perceptores de rentas elevadas y la desigualdad urbana. Se aprecia una relación positiva y una reducida dispersión. El coeficiente de correlación de la tabla 4 confirma el resultado; es positivo, cercano a 1 y significativo. Existe una relación positiva entre la segregación de las rentas elevadas y la desigualdad.

La tercera sección de la figura 4 muestra la relación entre la segregación de la población inmigrante y la desigualdad. No se aprecia una relación clara entre ambas variables. El coeficiente de correlación de la tabla 4 es negativo, reducido y poco significativo. En todo caso, parece haber una asociación negativa pero no muy significativa.

Los resultados apuntan a que la segregación de los perceptores de rentas altas es más determinante en relación a la renta salarial y a la desigualdad que la segregación de las rentas bajas y de la población inmigrante. Como hemos mostrado, las ciudades con mayor renta salarial y mayor desigualdad presentan una mayor segregación de las rentas elevadas. Recordemos por último que la correlación no implica causalidad y pueden considerarse argumentos teóricos en favor de ambas hipótesis. 

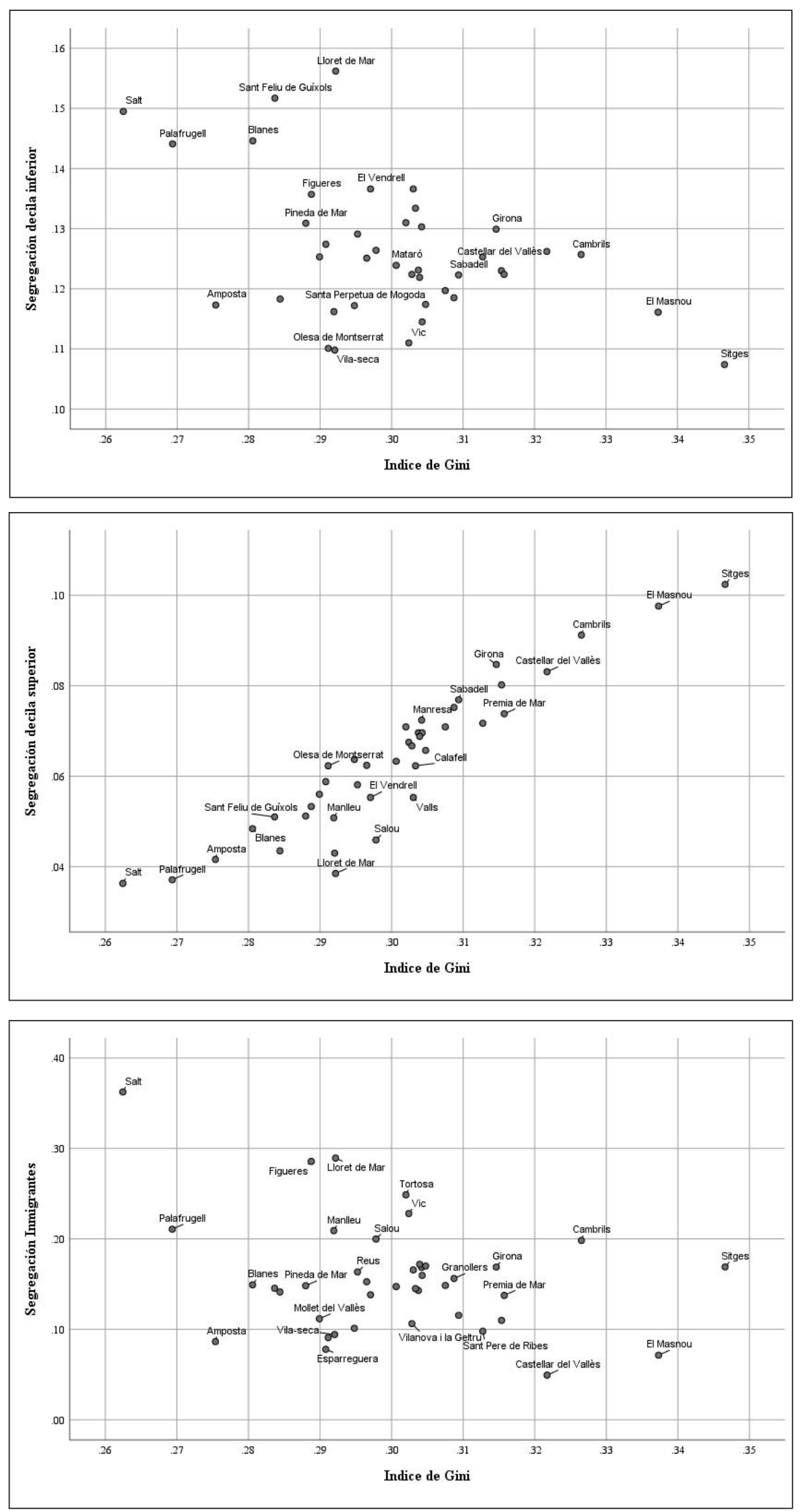

Figura 3. Desigualdad y segregación: a) segregación del decil inferior. b) segregación del decil superior. c) segregación de inmigrantes. 


\section{Análisis Cluster}

Con el objetivo de clasificar el conjunto de ciudades medianas y crear una tipología, se ha llevado a cabo un análisis cluster. Primero se han escogido diversas variables socioeconómicas que caracterizan las ciudades con información procedente del año 2011. El análisis cluster permite obtener una agrupación de ciudades maximizando la homogeneidad dentro de cada grupo y la heterogeneidad entre los grupos. Finalmente, se ha analizado la evolución de la renta y la desigualdad en el periodo 20012011 en cada grupo de ciudades.

Las características socioeconómicas medidas en cada ciudad tienen en consideración diversas perspectivas. Desde el punto de vista del mercado de trabajo, las variables seleccionadas son la tasa de actividad, la tasa de empleo, el porcentaje de mujeres ocupadas, el porcentaje de desocupados y un índice de especialización sectorial. Se ha optado por utilizar el índice de especialización de Krugman ${ }^{21}$, un índice relativo que compara las tasas de empleo por sector con las de Catalunya. Se calcula el valor absoluto de las diferencias para cada sector y ciudad y se suman. Valores próximos a cero implican una estructura sectorial similar a la de Cataluña, valores superiores implican mayores diferencias. También se han seleccionado dos variables que miden el impacto de la inmigración: el porcentaje de inmigrantes y el índice de segregación de inmigrantes utilizado previamente (DPxx). Asimismo, se han incorporado dos variables para medir el nivel educativo: el porcentaje de población con bajo nivel educativo (nivel máximo Graduado Escolar) y el porcentaje de población con estudios universitarios. Finalmente, otras características consideradas son la población (en logaritmos), la distancia por carretera a Barcelona y dos variables cualitativas binarias: un indicador de si la ciudad es la capital de una comarca o no y un indicador de si la ciudad forma parte de la región metropolitana de Barcelona (RMB) o no.

De las 41 ciudades analizadas, 19 son capitales de comarca (de las que 6 pertenecen a la RMB y 13 no) y 22 no lo son (12 en la RMB y 10 fuera). La Figura 4 muestra un diagrama de segmentos que caracteriza cada ciudad en función de la importancia que tiene cada una de las variables cuantitativas. Para cada ciudad, un segmento (y un color) representa una variable cuantitativa y su longitud indica la importancia relativa de la magnitud con respecto a la distribución de los 41 valores. Así, por ejemplo, en Terrassa destacan valores elevados de la población, del porcentaje de mujeres ocupadas y de la tasa de empleo y, por el contrario, valores bajos del índice de especialización y de la distancia a Barcelona. Las ciudades en la Figura 4 se muestran en un orden decreciente con la población: véase, de izquierda a derecha, la disminución de la longitud del segmento que representa al logaritmo de la población.

Desarrollamos a continuación un Análisis Cluster (AC) por el método jerárquico aglomerativo. Existe un elevado número de métodos de AC y conviene recordar que es posible obtener distintos resultados según el método elegido. La primera

21 Krugman, 1991b 


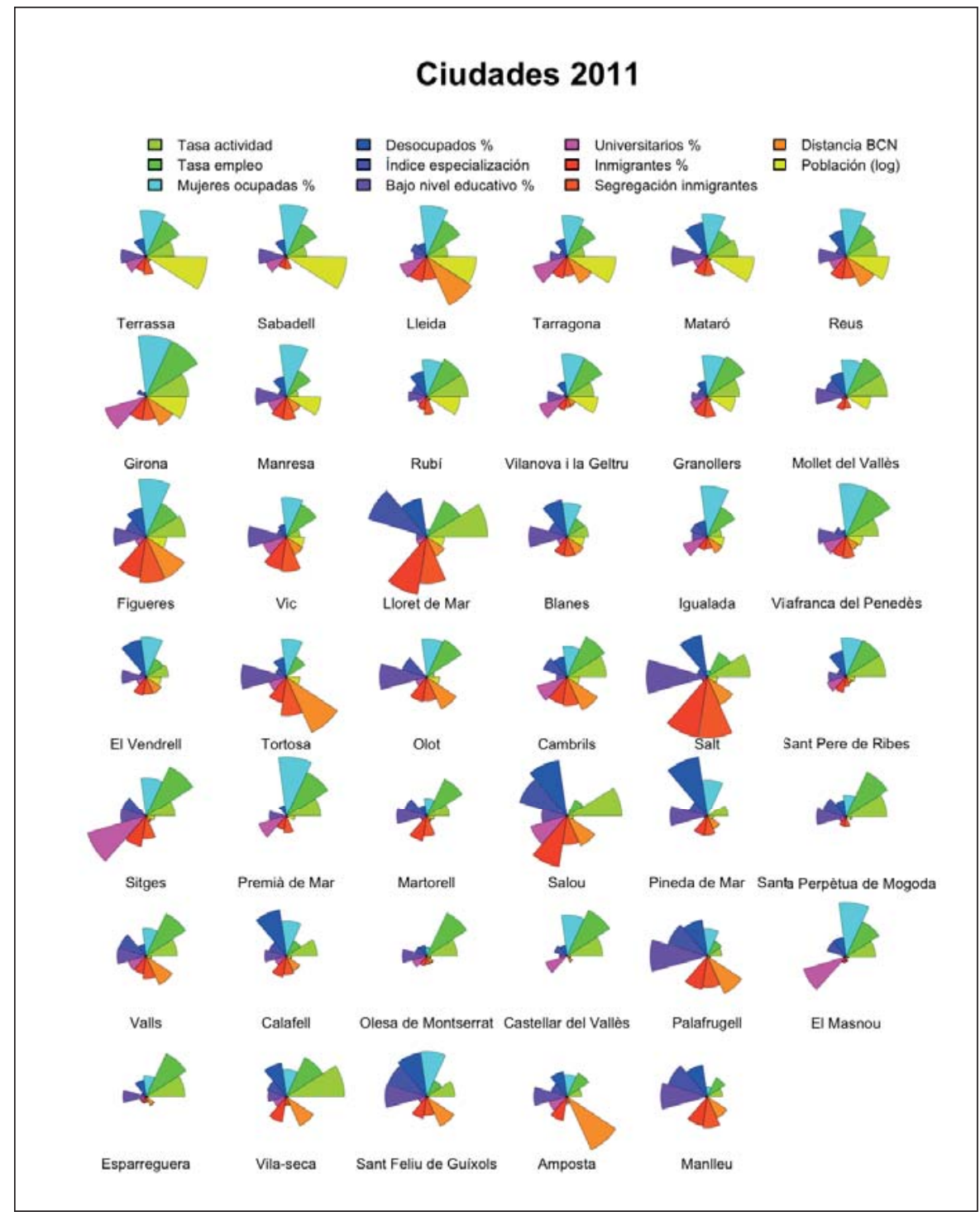

Figura 4. Características socio-económicas de las ciudades

elección ha sido la manera de medir la distancia entre ciudades; dada la naturaleza de las variables (cuantitativas y cualitativas) se ha escogido la distancia de Gower ${ }^{22}$. Se define como:

$$
d(x, y)=\frac{1}{k} \sum_{j=1}^{k} d\left(x_{j}, y_{j}\right)
$$

donde los vectores $x=\left(x_{1}, \ldots, x_{k}\right)$ y $y=\left(y_{1}, \ldots, y_{k}\right)$ representan las características cuantitativas y cualitativas de dos ciudades y los componentes $x_{j}$ y $y_{j}(j=1, \ldots, k)$ son los valores de la variable j-ésima de estas ciudades. Si las variables son cuantitativas: $d\left(x_{j}, Y_{j}\right)=\left|x_{j}-y_{j}\right| /($ max-min $)$. Si las variables son cualitativas binarias, $d\left(x_{j}, y_{j}\right)$ es la distancia de Jaccard, que toma el valor 0 si hay coincidencia y 1 si no la hay. Las ciudades más similares (con menor distancia de Gower) son: primero Terrassa y Sa- 
badell $(0,044)$, segundo Rubí y Mollet del Vallès $(0,055)$, tercero Santa Perpètua de Mogoda y Esparreguera $(0,064)$. Las ciudades más disimilares (con mayor distancia de Gower) son: primero Sabadell y Salou $(0,596)$, segundo Sabadell y Lloret de Mar $(0,581)$, tercero Sabadell y Salt $(0,574)$. En este punto, cabe mencionar que Salou, Lloret de Mar y Salt son ciudades que, en general, presentan unas características particulares que dan lugar a distancias elevadas con respecto a la mayoría del resto de ciudades.

La segunda elección en el AC es la distancia entre grupos: se ha utilizado el método de los vecinos más lejanos o distancias máximas. Así, la distancia entre dos grupos $C_{1}$ y $C_{2}$ viene definida de la siguiente manera:

$$
d\left(C_{1}, C_{2}\right)=\max _{x \in C_{1} y \in C_{2}} d(x, y)
$$

El dendrograma de la Figura 5 muestra el resultado del método de agrupación aglomerativo: la semejanza entre 2 grupos viene dada por la altura del nodo común más próximo.

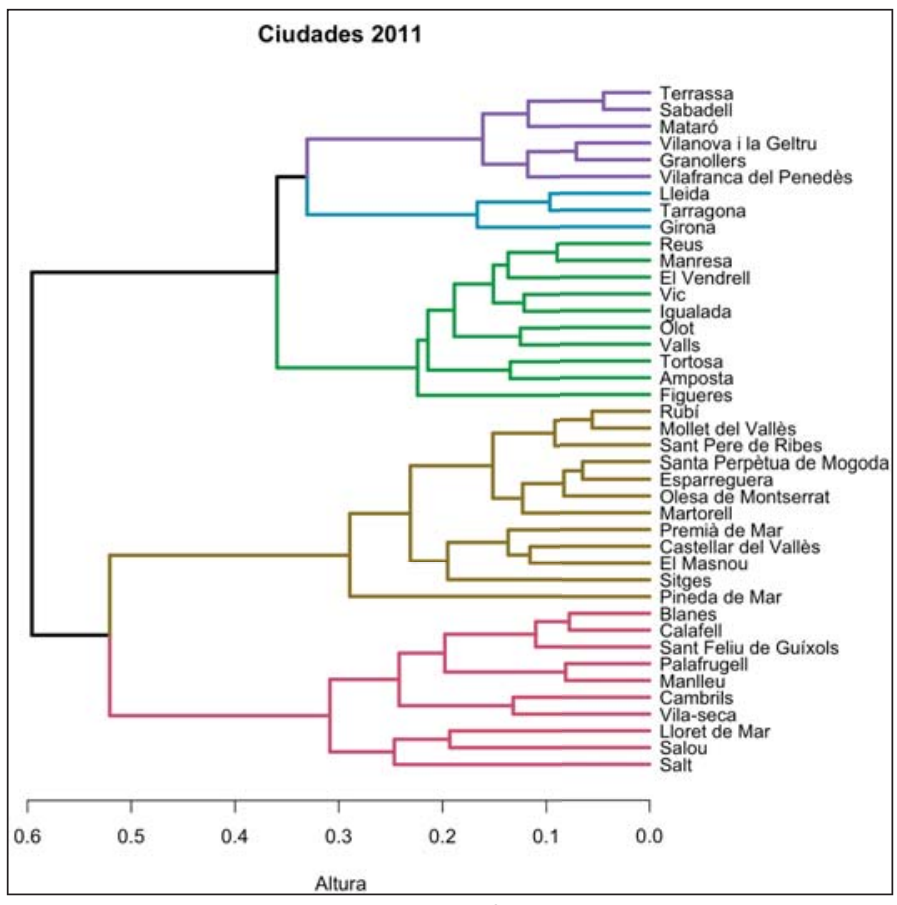

Figura 5. Dendrograma de ciudades y definición de grupos.

Finalmente, en vista del dendrograma resultante, la tercera elección en el AC es el número de grupos. En base al criterio de que las ciudades sean homogéneas dentro de cada grupo y heterogéneas respecto a las ciudades de otros grupos, se han considerado cinco categorías de ciudades medianas:

- Grupo 1: Terrassa, Sabadell, Mataró, Vilanova i la Geltrú, Granollers y Vilafranca del Penedès. Son seis ciudades que son capitales de comarca y forman parte de la RMB. 
- Grupo 2: Lleida, Tarragona y Girona. Lo forman las tres capitales de provincia (y también de comarca).

- Grupo 3: Reus, Manresa, Figueres, Vic, Igualada, El Vendrell, Tortosa, Olot, Valls y Amposta. Las diez ciudades de este grupo son capitales de comarca y no forman parte de la RMB.

- Grupo 4: Rubí, Mollet del Vallès, Sant Pere de Ribes, Sitges, Premià de Mar, Martorell, Pineda de Mar, Santa Perpètua de Mogoda, Olesa de Montserrat, Castellar del Vallès, El Masnou y Esparreguera. Son doce ciudades que pertenecen a la RMB pero no son capitales comarcales.

- Grupo 5: Lloret de Mar, Blanes, Cambrils, Salt, Salou, Calafell, Palafrugell, Vila-seca, Sant Feliu de Guíxols y Manlleu. Está compuesto por diez ciudades que no son capital de comarca y no forman parte de la RMB.

Una vez establecida la tipología de las ciudades, nos centramos en analizar la distribución de la renta salarial en 2011 y la evolución en el periodo 2001-2011 para cada grupo y desde tres perspectivas: el valor medio (en los gráficos, media), la desigualdad medida mediante el índice de Gini y las ratios entre el percentil 90 y el 50 (P90/P50) y entre el percentil 50 y el 10 (P50/P10) y, por último, la segregación por ingresos medida con los índices de aislamiento del decil superior de la renta (DPxx90) y del decil inferior (DPxx10).

En el caso de la renta salarial de 2011, la Figura 6 muestra la distribución de cada medida según las categorías establecidas. Los grupos 1 y 2 se corresponden, en general, con ciudades con mayor renta media, mayor desigualdad y mayor segregación de la población con rentas altas. Estas características están más acentuadas en el grupo 2 que en el grupo 1, excepto para las medidas de segregación. Ambos grupos muestran valores superiores de la ratio P90/P50, indicando que la mayor desigualdad observada con el índice de Gini, se origina en la mitad superior de la distribución. Por el contrario, las ciudades del grupo 5 tienen menor renta media, menor desigualdad, menor segregación de las rentas altas pero también mayor segregación de las rentas bajas. También puede apreciarse que la ratio P50/P10 es la menor de todos los grupos, indicando una elevada concentración de ingresos salariales en la mitad inferior de la distribución. Finalmente, las ciudades de los grupos 3 y 4 tienen una configuración intermedia respecto a los grupos contrapuestos anteriormente: en general presentan valores (de renta media, desigualdad y segregación de rentas altas) menores que los grupos 1 y 2 y mayores que el grupo 5. Los grupos 3 y 4 presentan mayor dispersión para cada una de las variables pero las medianas están muy cercanas excepto en el caso de la segregación de las rentas bajas.

La Figura 7 muestra la variación porcentual de las medidas de la renta en el periodo 2001-2011. Se observa una disminución general de la renta media, la desigualdad y la ratio P90/P50 y también de la segregación de la población con rentas altas. Por el contrario, la segregación de las rentas bajas aumenta y la desigualdad cuantificada con la ratio P50/P10 aumenta en los grupos 1 y 4 y no muestra una tendencia clara para el resto de los grupos. La disminución de la renta media es menor 


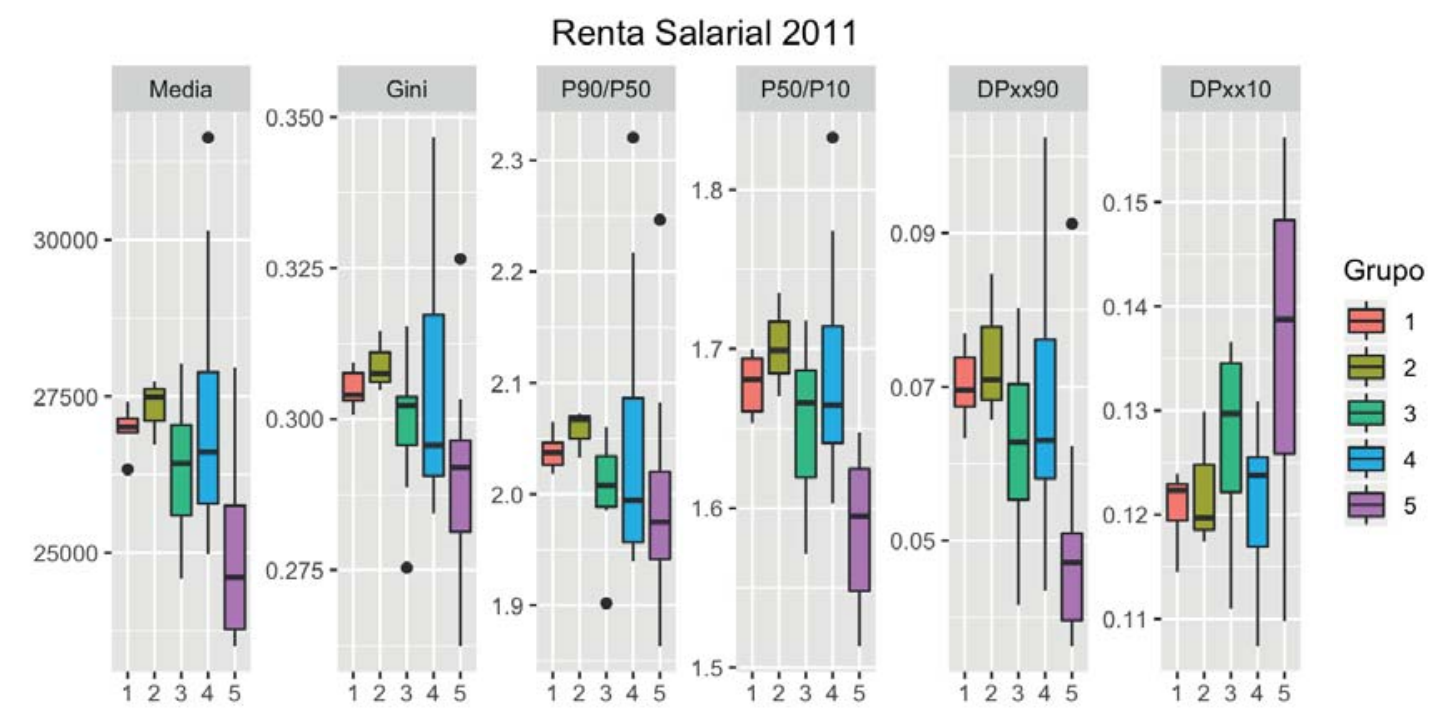

Figura 6. Renta Salarial, desigualdad y segregación por ingresos en cada tipo de ciudades

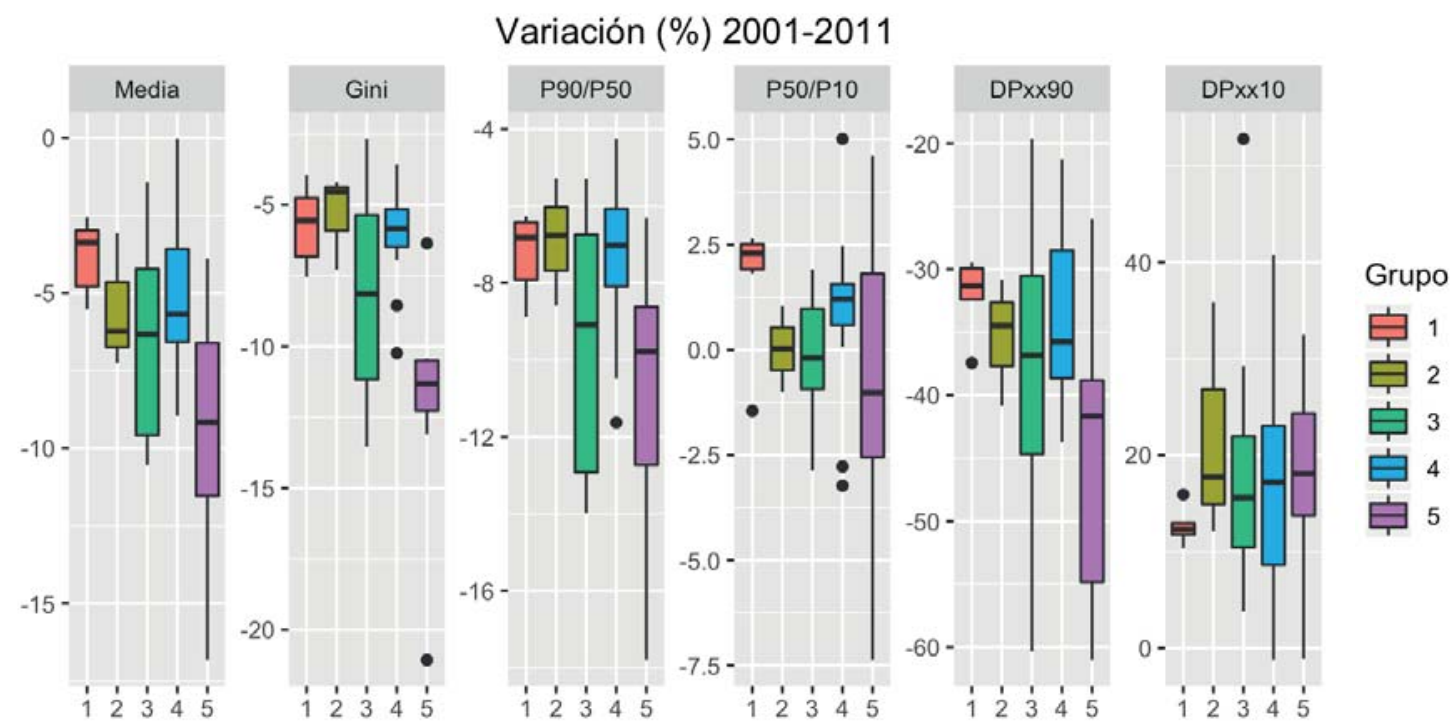

Figura 7. Cambios en la Renta Salarial, la desigualdad y la segregación por ingresos en cada tipo de ciudades

en el grupo 1 y mayor en el grupo 5. La reducción de la desigualdad medida con el índice de Gini y la ratio P90/P50 es pequeña en los grupos 1, 2 y 4 (cerca del 5\%), y en cambio es elevada en el grupo 5 (mayor que el 10\%). La segregación de las rentas elevadas disminuye en todos los grupos, pero en los grupos 1 y 2 se sitúa entre un $30 \%$ y un $40 \%$ mientras en el grupo 5 supera el $40 \%$. Finalmente, la segregación de las rentas bajas aumenta en todos los grupos pero el aumento es claramente menor en el grupo 1. El análisis cluster pone de manifiesto que se han producido trayectorias diversas para cada uno de los grupos de ciudades, en un contexto general de reducción de la renta salarial, la desigualdad, la ratio P90/P50, la segregación de las rentas altas y de aumento de la segregación de las rentas bajas. La ratio P50/P10 muestra comportamientos diferentes para cada grupo. 


\section{Conclusiones}

Las ciudades medianas de Cataluña han experimentado durante el periodo 20012011 una reducción de la renta salarial. Este resultado tiene su origen en los efectos de la gran recesión (2008-2011), dado que la primera parte de la década se caracterizó por un intenso crecimiento económico. Esta reducción de la renta salarial se debe tanto a la eliminación de puestos de trabajo con salarios elevados como a la proliferación de bajos salarios.

Este proceso de reducción de la renta salarial ha ido acompañado de una disminución de la desigualdad medida con el índice de Gini. Ambas variables muestran una elevada correlación positiva. Este resultado aporta evidencia empírica adicional a otros trabajos, centrados en ciudades grandes, donde se señala que el aumento de la renta es el principal factor causante de la desigualdad. La hipótesis que justifica esta relación es que el crecimiento de la renta salarial se debe a la aparición y proliferación de puestos de trabajo con elevados salarios que aumentan la dispersión y con ella, la desigualdad.

En cuanto a la relación entre la renta salarial y la segregación, los resultados muestran una correlación negativa con la segregación de las rentas bajas y con la segregación de la población inmigrante. En cambio, se obtiene una correlación positiva entre la renta salarial y la segregación de las rentas altas. Además, esta última es mayor y más significativa. En las ciudades con mayor renta salarial las familias de rentas elevadas tienden a estar más concentradas en determinadas zonas de la ciudad.

La desigualdad muestra una correlación negativa con la segregación del decil inferior (rentas más bajas) y con la población inmigrante. En las ciudades donde la desigualdad es menor, los hogares de renta baja y los de familias inmigrantes no están tan separados. En cambio, la desigualdad muestra una correlación positiva con la segregación de las rentas altas. En las ciudades en las que la desigualdad es mayor, los hogares de rentas altas tienden a estar más segregados, más agrupados espacialmente.

De este conjunto de resultados inferimos que la segregación de los hogares con rentas altas es más determinante en relación a la renta salarial y a la desigualdad. Las pautas de localización de las rentas altas, que tienen más posibilidades de escoger su localización y de abandonar zonas de la ciudad y relocalizarse en otras más acordes con sus preferencias es un elemento importante para analizar las dinámicas urbanas. También hay que tener presente que las familias con rentas elevadas pueden tener mayor capacidad política para influir en la planificación urbana. Por último, la progresiva separación de los hogares en función de su nivel de renta y especialmente la separación de los hogares de renta alta puede debilitar el apoyo político a las medidas de redistribución ${ }^{23}$ y puede limitar el efecto demostración que ejerce sobre las decisiones de inversión educativa.

23 Bailey et al. 2013 
El análisis Cluster que hemos desarrollado utilizando 11 variables socioeconómicas cuantitativas y 2 cualitativas ha permitido obtener una tipología de ciudades medianas. Hemos obtenido una clasificación de cinco grupos. Los dos primeros, formados por seis capitales comarcales que pertenecen a la RMB y las tres capitales de provincia presentan mayor renta salarial, asociada a mayor desigualdad y mayor segregación de rentas altas. También presentan valores superiores de la ratio P90/ $\mathrm{P} 50$, indicando que la mayor desigualdad proviene de la mayor presencia de salarios elevados. En el otro extremo, el grupo 5 está formado por 10 ciudades que no son capitales comarcales ni pertenecen a la RMB. Presentan menor renta salarial, menor desigualdad y menor segregación de rentas elevadas, pero mayor segregación de rentas bajas. También, se observa un menor valor de la ratio P50/P10 que implica una elevada concentración de rentas salariales bajas. Son en su mayoría ciudades costeras con una actividad económica muy estacional ligada al turismo masivo. Se incluyen también en este grupo Salt y Manlleu, dos ciudades con características particulares. La primera es la ciudad con el mayor porcentaje de población inmigrante de Cataluña. La segunda es una ciudad con una concentración industrial destacable en el pasado que ha perdido esa base industrial y que ha mostrado dificultades para atraer y mantener actividad del sector servicios que compensara esa pérdida.

Los grupos 3 y 4 , formados respectivamente, por diez ciudades que son capitales comarcales no localizadas en RMB y doce ciudades que no son capitales comarcales pero situadas en la RMB, presentan una configuración intermedia en la renta salarial, la desigualdad y la segregación de rentas altas. Las medidas relacionadas con la renta y su distribución presentan mayor dispersión, aunque las medianas de cada variable son parecidas, excepto en el caso de la segregación de las rentas bajas, en el que el grupo 3 presenta valores superiores.

Teniendo presente esta clasificación de las ciudades medianas, se aprecia una reducción de la renta salarial que ha afectado menos al grupo 1 y más al grupo 5. Esta reducción ha ido acompañada de una reducción de la desigualdad, más pronunciada en el grupo 5, y de la ratio P90/P50, más acusada en los grupos 3 y 5 . Este proceso ha venido acompañado de una reducción importante de la segregación de rentas elevadas y un aumento generalizado de la segregación de las rentas bajas.

Los resultados aquí obtenidos apuntan a la relación entre desigualdad de los ingresos salariales y la segregación por ingresos y a las pautas de especialización sectorial de las ciudades medianas como dos objetos para futuras investigaciones. Respecto al primer tema, la literatura analizada proporciona evidencia empírica de que la desigualdad de ingresos es un factor que impulsa la segregación por ingresos. Nuestros resultados indican que ambos fenómenos están relacionados pero sería necesario profundizar en esa relación para obtener una perspectiva más clara. Además, debería analizarse también si la mayor segregación por ingresos realimenta también la desigualdad de ingresos. Respecto a la segunda cuestión, nuestros resultados apuntan a que los patrones de especialización sectorial de las ciudades medianas son relevantes para conocer qué tipo de puestos de trabajo y qué niveles sala- 
riales se localizan en las ciudades medianas y por tanto, cómo evoluciona la renta salarial y la desigualdad.

Desde un punto de visto político, este trabajo apunta a la necesidad de desarrollar medidas específicas para cada tipo de ciudad, teniendo en cuenta las características sociales, económicas y geográficas. Por otro lado, las políticas urbanas y de vivienda deberían tener presente los niveles de segregación, tanto de ingresos como de la población inmigrante para evitar un aumento de la segregación que aumente la distancia entre las condiciones sociales y económicas diferentes y separadas que generen o agraven problemas sociales. Un último aspecto destacable es la necesidad de repensar las políticas laborales que combatan la proliferación de puestos de trabajo con bajos salarios y malas condiciones laborales que son el origen de la desigualdad y la segregación.

\section{Referencias Bibliográficas}

ANDRÉS LÓPEZ, Gonzalo (2008) Geografía y Ciudades Medias en España: ¿A la búsqueda de una definición innecesaria? Scripta Nova. Revista Electrónica de Geografía y Ciencias Sociales. vol. XII, no 270 (49).

APPARICIO, Philippe; MARTORI, Joan Carles, PEARSON, Amber L., FOURNIER, Éric, APPARICIO, Denis (2014) An Open-Source Software for Calculating Indices of Urban Residential Segregation. Social Science Computer Review. vol. $32, \mathrm{n}^{\circ} 1, \mathrm{p} .117-128$

BAILEY, Nick; GANON, Maria; KEARNS, Ade; LIVINGSTON, Mark; LEYLAND, ALASTAIR H. (2013) Living apart, losing sympathy? How neighbourhood context affects attitudes to redistribution and to welfare recipients.

Environment and Planning A: Economy and Space. Vol. 45, nº 9, p. 2154-2175

BOLTON, Kenyon; BREAU, Sébastien (2012) Growing unequal? Changes in the distribution of earnings across Canadian cities. Urban Studies, vol. 49, nº 6, p. 1377-1396

BRINDUSA, Anghel; BASSO, Henrique: BOVER, Olympia; CASADO, José María: HOSPIDO, Laura; IZQUIERDO, Mario; KATARYNIUK, Ivan A.; LACUESTA, Aitor; MONTERO, José Manuel; VOZMEDIANO, Elena (2018) Income, consumption and wealth inequality in Spain. Occasional papers $n^{\circ} 1806$. Banco de España

CAMAGNI, Roberto; CAPELLO, Roberta; CARAGLIU, Andrea (2015) The rise of second-rank cities: What role for agglomeration economies? European Planning Studies Vol 23, nº 6, p. 1069-1089

DAVID, Quentin; PEETERS, Didier; Van HAMME Guilles; VANDERMOTTEN, Christian (2013) Is bigger better? Economic performances of European cities, 1960-2009. Cities. Vol. 35, p. 237-254

DABLA-NORRIS, Era; KOCHLAR, Kalpana; SUPHAPHIPHAT, Nujin; RICKA, Frantisek, TSOUNTA Evridiki (2015) Causes and consequences of income inequality: a global perspective. Technical report. Washington; IMF. 
DIJKSTRA, Lewis; POELMAN, Hugo (2012) Cities in Europe. The new OECD-EU definition. Regional Focus 01/2012. Directorate-General for Regional and Urban Policy. European Commission

DIJKSTRA, Lewis; GARCILAZO, Enrique; McCANN, Philip (2013) The economic performance of European cities and city regions: Myths and realities. European Plannning Studies. Vol. 21, nº 3, p. 334-354

EUROPEAN COMMISSION (2011) Cities of tomorrow - Challenges, visions, ways forward. Luxembourg: Publications Office of the European Union. 112 p. FLORIDA, Richard (2017) The New Urban Crisis. New York: Basic Books. 311 p. GLAESER, Eduard L.; KALLAL. Heidi D.; SCHEINKMAN, José A. SHLEIFER, Andrei ( 1992 ) Growth in cities. Journal of Political Economy, vol. 100, nº 6, p. 11261152.

GLAESER, Eduard L.; RESSEGER, Matt; TOBIO, Kristina (2009) Inequality in cities. Journal of Regional Science, vol. 49, n 4, p. 617-646

GOWER, J. C. ( 1971) A general coefficient of similarity and some of its properties. Biometrics, vol. 27, p. 857-874

KRUGMAN, Paul (1991a) Geography and Trade. Cambridge, MA: Cambridge University Press. 156 p.

KRUGMAN, Paul (1991b) Increasing returns and economic geography. Journal of Political Economy, Vol. 99, n³, p. 483-499

LEE, Neil; SISSONS, Paul; JONES, Katy (2016) The geography of wage inequality in British cities. Regional Studies, vol. 50, $\mathrm{n}^{\circ} 10, \mathrm{p} .1714-1727$

MADARIAGA, Rafa; MARTORI; Joan Carles; OLLER, Ramon (2012) Distribución Espacial y Desigualdad de la Renta Salarial en el Área Metropolitana de Barcelona. Scripta Nova. Revista Electrónica de Geografía y Ciencias Sociales. Vol. XVI, no 405

MADARIAGA, Rafa; MARTORI; Joan Carles; OLLER, Ramon (2019) Wage income inequality in Catalonian second-rank cities. Annals of Regional Science. https://doi.org/10.1007/s00168-019-00896-0

MASSEY, Douglas S.; DENTON, Nancy A. (1988). The dimensions of residential segregation. Social Forces, vol. 67, no 2, p. 281-315,

MORGAN, Barrie S. (1983). A distance-decay based interaction index to measure residential segregation. Area, vol. $15 \mathrm{n}^{\circ}$ 3, p. 211-217.

MUSTERD, Sako; MARCIŃCZAK, Szymon; VAN HAM, Maarten; TAMMARU, Tiit (2017) Socioeconomic segregation in European capital cities. Increasing separation between poor and rich. Urban Geography, vol 37, nº 7, p. 1062-1083

OECD (2011) Divided we stand: why inequality keeps rising. Country note: Spain. Technical report. Paris; OECD.

OECD (2015) In it together: why less inequality benefits all. Technical report. Paris; OECD.

PARKINSON, Michael; MEEGAN, Richard; KARECHA, Jay (2015) City size and economic performance: Is bigger better, small more beautiful or middling 
marvellous? European Planning Studies. Vol. 23, nº 6, p. 1054-1068 QUILLIAN, Lincoln; LAGRANGE, Hugues (2016) Socioeconomic Segregation in Large Cities in France and the United States. Demography Vol. 53, no 4, p. 1051 1084

REARDON, Sean F.; BISCHOFF, Kendra (2011) Income Inequality and Income Segregation. American Journal of Sociology. Vol. 1 16, nº 4, p. 1092-1153 ROCA CLADERA, Josep; MOIX BERGADÀ, Montserrat; ARELLANO RAMOS, Blanca. (2012) El sistema urbano en España. Scripta Nova. Revista Electrónica de Geografía y Ciencias Sociales. Vol. XVI, nº 395.

TAMMARU, Tiit; MARCIŃCZAK, Szymon; AUNAP, Raivo; VAN HAM, Maarten; JANSSEN, Heleen (2019) Relationship between income inequality and residential segregation of socioeconomic groups. Regional Studies.

https://doi.org/10.1080/00343404.2018.1540035

TILFORD, Simon (2016) Gain or more Pain in Spain. Centre for European Reform. Policy Brief. https://www.cer.eu/publications/archive/policy-brief/2015/gainor-more-pain-spain (Consulta: Febrero 2019)

VAN HAM, Maarten; MARCIŃCZAK, Szymon; TAMMARU, Tiit; MUSTERD, Sako (2015) Socio-Economic Segregation in European Capital Cities: East Meets West. London: Routledge, 416 p.

UXÓ, Jorge; FEBRERO, Eladio; BERMEJO, Fernando (2016) Crisis, unemployment and internal devaluation in Spain, In MYANT, Martin; THEODOROPOULOE, Sotiria; PIASNA, Agnieszka Unemployment, Internal Devaluation and Labour Market Deregulation in Europe. Brussels: ETUI.

WORLD BANK (2016) Poverty and shared prosperity 2016: taking on inequality. Technical report. Washington; World Bank.

(c) Copyright: Rafa Madariaga, Joan Carles Martori, Ramon Oller, 2020

(c) Copyright: Scripta Nova, 2020.

Ficha bibliográfica:

MADARIAGA, Rafa; MARTORI, Joan Carles; OLLER, Ramon. Renta salarial, desigualdad y segregación residencial en las ciudades medianas de Cataluña. Scripta Nova. Revista Electrónica de Geografía y Ciencias Sociales. Barcelona: Universidad de Barcelona, 15 de Junio de 2020, vol. XXIV, $n^{0}$ 640. [ISSN: 1138-9788] 